ORIGINAL ARTICLE

\title{
Risk factors for occupational knee related disability among enlisted women in the US Army
}

\author{
S I Sulsky, K A Mundt, C Bigelow, P J Amoroso
}

Occup Environ Med 2002;59:601-607

See end of article for authors' affiliations .....................

Correspondence to: Dr Sulsky, Applied Epidemiology, Inc., PO Box 2424, Amherst, MA 01004,USA; ssulsky@ appliedepidemiology.com

This work was funded by the National Institute of Occupational Safety and Health, grant number 1 RO3-OH037387-01A1

Accepted 10 April 2002

\begin{abstract}
Aims: To identify sociodemographic and occupational determinants of knee related disability discharge from the US Army among enlisted women, and to investigate effect modification.

Methods: A case-control study of 692 cases of knee related disability discharge and 2080 incidence density matched controls nested within the population of all 244000 enlisted women on active duty in the US Army, 1980-97. We used logistic regression to identify determinants of disability, stratified to explore effect modification by demographic and work characteristics.

Results: The risk of disability discharge was twice as high (odds ratio (OR) 2.4, 95\% confidence interval (CI): 1.71 to 3.47 ) for the oldest (33-60 years) versus the youngest (17-21 years) women. Nonwhites had lower risk than whites (OR $0.5,95 \% \mathrm{Cl}: 0.41$ to 0.60 ), as did married (OR $0.7,95 \% \mathrm{Cl}$ : 0.54 to 0.81 ) relative to non-married women. Those of lower rank (pay grades E 1-E3) were at five times the risk of disability discharge compared to those of higher ranks (pay grades E4-E9, OR 5.0, $95 \% \mathrm{Cl}: 2.86$ to 8.33 ), while ORs were highest for those with longer duration of service compared to women on active duty for a year or less (OR $1.4,95 \% \mathrm{Cl}: 0.8$ to 2.55 after 12 years). Race modified several effects, including that of rank. Age, duration of service, and pay grade were too highly correlated to draw firm conclusions about their independent modifying effects on risk of disability discharge from the Army.

Conclusions: Sociodemographic factors had larger effects than occupational characteristics on risk of knee related disability discharge from the US Army. Interactions suggest subgroups at differing risk levels that might be targeted for more detailed investigations.
\end{abstract}

$\mathrm{D}$ uring calendar year 2000, cases of occupational illnesses and injuries in the United States occurred at the rate of 6.1 per 100 full time equivalents (FTE). Injuries accounted for the vast majority of these cases, 5.8/100 FTE. ${ }^{1}$ The consequences of occupational injuries include physical, psychological, and economic components for the injured worker, and also affect coworkers and employers. ${ }^{2}$ Although the majority of occupational musculoskeletal injuries heal successfully, some result in long term or permanent disability. Extended periods of lost work time as a result of occupational disability add to the human and the economic costs, both for the person injured and the employer.

\section{Occupational musculoskeletal disabilities}

A large proportion of occupational injuries affect the musculoskeletal system. ${ }^{3}$ During fiscal year 1994, for example, musculoskeletal conditions accounted for $53 \%$ of all disability discharges from the US Army. The next most common category of disability discharge, mental disorders, accounted for only $14 \%$ of disabilities. ${ }^{45}$

Among occupational musculoskeletal injuries and disabilities, the knee is one of the most common sites of occurrence. Physical demands have been associated with knee injuries and subsequent long term knee disorders. These demands may be associated with occupational activities, such as sustaining static loads, lifting, and prolonged kneeling..$^{6-10}$ Leisure activities such as running and participation in sports have also been implicated in the development of knee injury and disability. ${ }^{11}{ }^{12}$

Knee related disabilities have been reported to vary across sociodemographic as well as occupational groups. Feuerstein et al found that the risk of discharge from the US Army for any musculoskeletal disability was higher for women compared to men between 1990 and 1994, and that risks were dependent on job code. For both men and women, knee impairments were the third most common reason for discharge from service. ${ }^{13}$ In a pilot study, we observed that the risk of discharge from the Army between 1980 and 1994 for all knee related disabilities depended on gender, race, and age, and there were complex interactions among these sociodemographic characteristics. ${ }^{14}{ }^{15}$

The purpose of this study was to identify independent occupational determinants of knee related disability discharge from the Army among enlisted women, taking into account the effect of sociodemographic characteristics. We restricted the study to women because of differences in baseline risk and risk factors experienced by men and women, described above. The study outcome of disability discharge from the US Army was used as a marker for severe injury; disability discharges in the Army are granted for conditions that impair one's ability to perform one's duty. We chose to conduct the study within the Army population for a number of practical and methodological reasons: (1) Its population consists largely of healthy individuals selected to be free of serious health conditions; preaccession physical examinations and interviews are conducted to rule out the presence of many pre-existing injuries and health conditions. (2) The wide range of jobs in the Army enables the analysis of a variety of occupational factors within the same population; civilian occupational injury studies typically focus on one or two specific jobs or tasks. (3) Many military jobs are physically demanding, representing high risk for injury and disability. (4) Large numbers of women and members of racial/ethnic minorities are employed by the Army,

Abbreviations: $\mathrm{Cl}$, confidence interval; $\mathrm{CMF}$, career management field; DMOS, duty military occupational specialty; FTE, full time equivalent; OR, odds ratio; PMOS, primary military occupational specialty; TAIHOD, Total Army Injury and Health Outcomes Database; VASRD, Veteran's Administration System for Rating Disability 


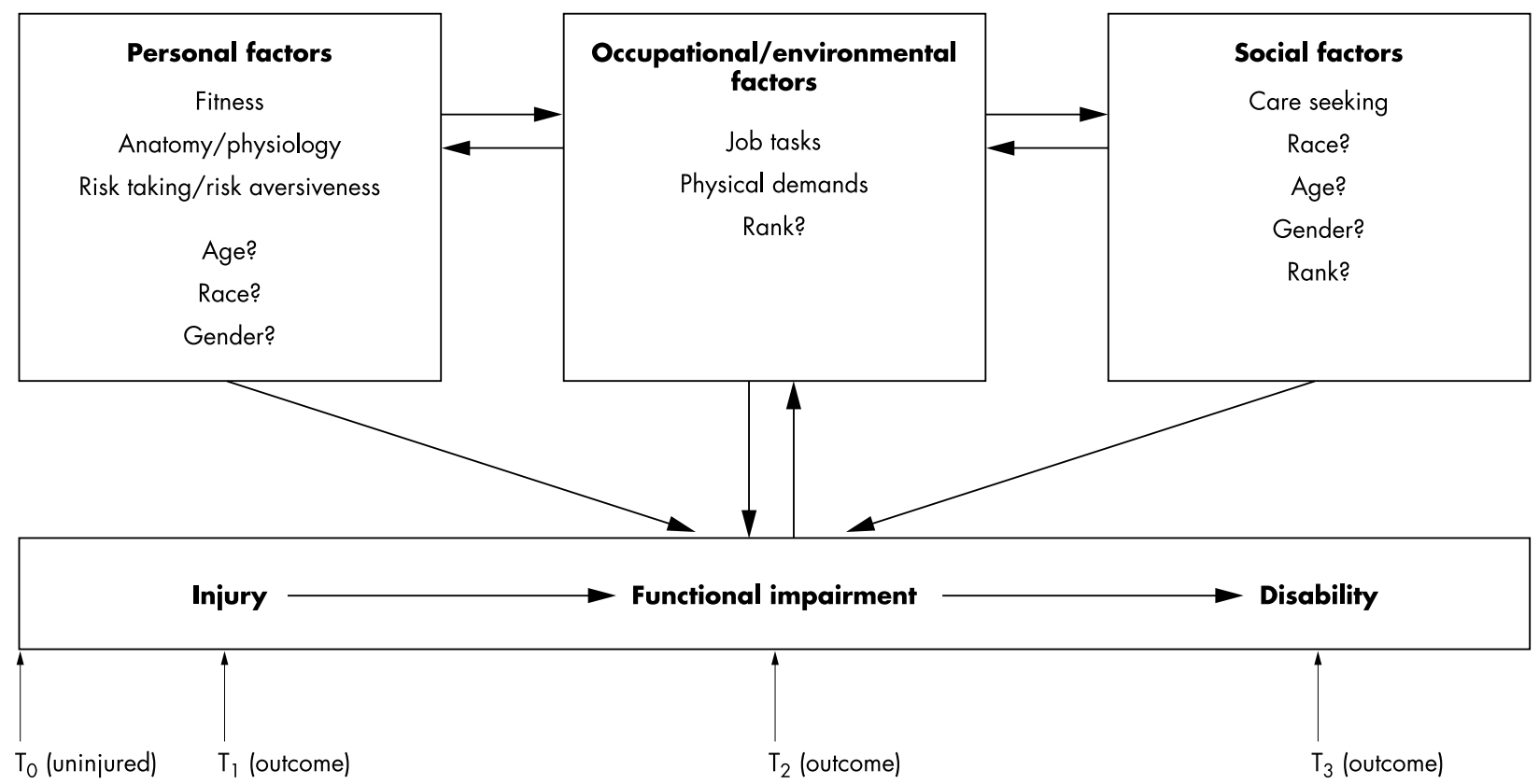

Figure 1 Conceptual model describing the inter-relation between personal, occupational/environmental, and social factors, and their impact on the progression from occupational injury to impairment to disability.

allowing for the investigation of demographic differences in risk. (5) Most military jobs are also represented in the civilian sector. Therefore, risk factors for occupational disability identified in the Army should also pertain to civilian workers.

\section{Conceptual model}

"Occupational disability" represents the culmination of a series of events, shown in fig 1 . This model is similar to one proposed by Burdorf et al in that it addresses the multidimensional and multidirectional nature of the relations to be considered in studies of injury and disability. ${ }^{16}$ The models differ, however, in focus: Burdorf et al use their model to help define the full range and timing of exposures that influence the progression from uninjured to disabled, while our model is meant to also assist in the development of research questions pertinent to any of the range of possible outcomes.

The figure shows the sequence of events for an individual initially free of a specific injury or disability $\left(\mathrm{T}_{0}\right)$, who either becomes injured or recognises an injury $\left(\mathrm{T}_{1}\right)$. Risk factors for this injury operate between $\mathrm{T}_{0}$ and $\mathrm{T}_{1}$. The injury may or may not require treatment, be treated appropriately, or heal. If healing is impossible or incomplete, some functional impairment may ensue $\left(T_{2}\right)$. Factors that influence healing operate between $T_{1}$ and $\mathrm{T}_{2}$; these may include factors or characteristics that also influence the risk of injury. If the impairment reaches some level of severity, a combination of medical and administrative evaluations may lead to a determination of occupational disability $\left(\mathrm{T}_{3}\right)$. This process and its duration are likely to be affected and modified by many factors. Some factors may operate only between $\mathrm{T}_{2}$ and $\mathrm{T}_{3}$, others may operate at various points, and still others may be in effect throughout the time line.

Determinants of occupational injury, impairment, and disability can be broadly grouped into three categories: personal, occupational/environmental, and social. Factors in any or all of these categories may play a role in an individual's progression from uninjured to disabled. Interactions among factors may also influence events at any point(s) in time. Aetiological research properly focuses on factors that operate before the injury $\left(T_{1}\right)$. However, functional impairment $\left(T_{2}\right)$ and disability $\left(\mathrm{T}_{3}\right)$ can be conceptualised as separate outcomes.

Different questions can be addressed by identifying factors that operate at different points along the time line. Some research questions may best be answered in analyses that take into account the initial injury occurrence (for example, risk factors for impairment given injury); others (for example, risk factors for disability) may be addressed without directly considering the causes of the initial injury. As a simple example, if employees of a particular manufacturing facility suffer low rates of injury, but high rates of occupational disability following injury (that is, low probability of return to work), then it would be both reasonable and efficient to focus research on factors that operate at $\mathrm{T}_{1}$ and later.

\section{MATERIALS AND METHODS \\ Data sources}

The Total Army Injury and Health Outcomes Database (TAIHOD) is a relational database linking demographic and occupational information with databases tracking hospitalisations, lost work time injuries, and disability determinations. At the time of these analyses, data were complete for all personnel on active duty in the Army from 1980 to 1998. The TAIHOD is updated annually, and currently consists of data for more than 2.5 million individuals. The structure and contents of TAIHOD have been described elsewhere. ${ }^{15}$

\section{Case definition}

Cases were identified from the disability database. After reviewing all disability codes in use, we identified 11 Veteran's Administration System for Rating Disability (VASRD) codes that might indicate a functional disability related to a knee problem (table 1). Some of the codes refer to conditions specific to the knee, while others more generally involve the lower leg.

Case records are the first recorded knee related disability finding for enlisted women who were on active duty in the regular Army during the calendar year of the disability determination, or the year prior. Since the database was compiled in 1980, the first recorded disability finding may not represent the first knee disability if the person was placed on temporary disability before 1980, or if the first disability determination occurred after 1980 but was not properly recorded in the database.

\section{Eligibility period for cases}

We did not include all eligible cases recorded in the TAIHOD, for two reasons. Firstly, preliminary analyses showed that the 
Table 1 Knee related disabilities and case counts for enlisted women in the US Army, based on Veteran's Administration System for Rating Disability (VASRD) codes, 1980-97

\begin{tabular}{|c|c|c|c|c|}
\hline \multirow[b]{2}{*}{ Disability name } & \multicolumn{2}{|c|}{ All cases } & \multicolumn{2}{|c|}{ Analysis set } \\
\hline & $\mathrm{n}$ & $\%$ & $\mathrm{n}$ & $\%$ \\
\hline Recurrent subluxation or lateral instability of knee & 635 & 63.5 & 459 & 65.38 \\
\hline Impairment of femur* & 188 & 18.8 & 129 & 18.38 \\
\hline Impairment of tibia and fibula $\dagger$ & 116 & 11.6 & 71 & 10.11 \\
\hline Removal of semilunar cartilage & 44 & 4.40 & 32 & 4.56 \\
\hline Genu recurvatum & 6 & 0.60 & 3 & 0.43 \\
\hline Dislocation of semilunar cartilage & 7 & 0.70 & 1 & 0.14 \\
\hline Knee replacement & 1 & 0.10 & 1 & 0.14 \\
\hline Thigh amputation & 1 & 0.10 & 0 & 0.00 \\
\hline Ankylosis of knee & 0 & 0.00 & 0 & 0.00 \\
\hline Amputation with loss of extrinsic pelvic girdle muscles & 0 & 0.00 & 0 & 0.00 \\
\hline Amputation $1 / 3$ of the distance from the perineum to the knee & 2 & 0.20 & 2 & 0.28 \\
\hline Total & 1000 & 100 & 702 & 100 \\
\hline
\end{tabular}

database might be less complete for 1980-82 compared to later calendar years (not shown). Secondly, in the Army, the administrative process of disability determination can take months or years to complete. In pilot data, the average interval between first recorded knee related hospitalisation and disability discharge was two years (not shown). Since we planned to use these data for a series of related analyses, it was important to define a source population that would be directly comparable across studies. Therefore, we excluded disability cases reported before 1984 to ensure reasonably complete case ascertainment, and cases reported after 1994 to ensure a sufficient interval between injury and disability determination for the administrative process to be completed. The latter was a consideration for other planned analyses A total of 702 enlisted women had knee related disability discharges and met the inclusion criteria for this period.

\section{Control definition}

Controls comprised a simple random sample from the population of all enlisted women with a record in the personnel file for a given year. We sampled controls from each year in proportion to the number of cases recorded in that year to approximate incidence density sampling for the study period. We excluded any potential control with a knee disability recorded in any year prior to the year from which she was sampled. We also excluded potential controls with pay grade indicating officer status, or with missing data for gender. Three controls for each case were included $(n=2106)$.

\section{Job codes and career management fields}

The TAIHOD records both primary military occupational specialty (PMOS) and duty military occupational specialty (DMOS). PMOS represents a job for which training was received, while DMOS codes the current duty assignment. In previous work, it was shown that PMOS was more often complete than DMOS, but, when both were recorded, the two codes tended to agree $(r>0.90) .{ }^{17}$ Given the high correlation, and assuming that a change in PMOS would represent a durable change in assignment, we used the PMOS to identify jobs. Preliminary analyses showed that the rate of job changes was low (less than one per year), and similar for cases and controls (not shown). Therefore, to categorise individuals by job title, we used the PMOS recorded during the 12 months prior to case/control identification.

There had been a number of revisions to PMOS coding by the Army during the study period. ${ }^{18}$ In order to map PMOS to occupational tasks, we revised obsolete codes that represented at least $1 \%$ of records in the data library (roughly the 50 most common PMOS) to follow the most current coding scheme. ${ }^{19}$ All PMOS were then coded to identify the presence or absence of specific physical task requirements according to the Military Occupational Classification and Structure Manual ${ }^{18}$ following the procedures developed by Williams. ${ }^{19}$ We also mapped PMOS to the eleven career management fields (CMF) used by the Army for research and administrative purposes.

\section{Statistical methods}

We used SAS version $6.12{ }^{20}$ for data management and analysis. We used $t$ tests, Mann-Whitney tests, and single predictor logistic regression models to identify terms with sufficient variability and/or a sufficiently strong crude association with the outcome to be included as candidates in multiple logistic regression models of the probability of knee related disability discharge. Because of the number of cases and controls being compared, and hence a high degree of statistical power (80-99\% power to detect a 5\% difference in proportions exposed with a type I error rate of $1-2 \%$, depending on exposure prevalence ${ }^{21}$ ), we developed a decision rule to identify candidate terms that would be of both practical and statistical importance. Candidates for the multivariable models were required to have both an odds ratio (OR) showing a 50\% change from the null value of $1.0(\mathrm{OR} \leqslant 0.67, \mathrm{OR} \geqslant 1.5)$ and $\mathrm{p} \leqslant 0.05$ in single predictor models.

The goal of this study was to identify occupational risk factors for knee related disability discharge from the Army while taking into account demographic characteristics that influence risk. Therefore, we first identified the best model to represent demographic predictors of risk from among those identified in preliminary analyses, then added individual work related covariates to the demographic model in order to identify their independent effects, if any. Terms that failed to contribute to the model according to the decision rule defined above were removed. A $20 \%$ change in any regression coefficient was taken to indicate important confounding by a previously excluded covariate, and that term was added back into the final model. ${ }^{22}$ We investigated effect modification by several characteristics identified a priori: race, age, duration of service, and pay grade. The goodness of fit of each final model (from the main analysis and from each stratified analysis) was evaluated using the Hosmer and Lemeshow statistic. ${ }^{22}$

\section{RESULTS}

Table 2 shows the demographic and occupational characteristics of cases and controls included in the analytical subset. The age distribution was similar for cases and controls, although cases were slightly more likely to be in the two oldest quintiles of age. Cases were also more likely to be white and more likely to be unmarried compared to controls. Cases were also over represented in the first two quintiles of duration of service. Perhaps because of their shorter service history, cases were more likely to 
Table 2 Sociodemographic characteristics of enlisted women in the US Army, 1984-94

\begin{tabular}{|c|c|c|c|c|c|}
\hline & \multicolumn{5}{|c|}{ Knee related disability discharge } \\
\hline & \multicolumn{2}{|c|}{ Cases $^{*}(n=702)$} & \multicolumn{2}{|c|}{ Controls $(n=2106)$} & \multirow[b]{2}{*}{ Unadjusted OR† } \\
\hline & $\mathrm{n}$ & $\%$ & $\mathrm{n}$ & $\%$ & \\
\hline \multicolumn{6}{|l|}{ Age quintiles $\ddagger$} \\
\hline $17-20$ years & 119 & 16.95 & 341 & 16.21 & 1.0 \\
\hline $21-22$ years & 119 & 16.95 & 395 & 18.77 & 0.86 \\
\hline $23-25$ years & 133 & 18.95 & 483 & 22.96 & 0.79 \\
\hline $26-32$ years & 206 & 29.34 & 568 & 27.00 & 1.04 \\
\hline $33-60$ years & 125 & 17.81 & 317 & 15.07 & 1.13 \\
\hline \multicolumn{6}{|l|}{ Race } \\
\hline Unknown & 1 & 0.14 & 3 & 0.14 & Not calculated \\
\hline White & 469 & 66.81 & 1050 & 50.0 & 1.0 \\
\hline Black & 198 & 28.21 & 916 & 43.49 & 0.59 \\
\hline Other & 34 & 4.84 & 137 & 6.36 & 0.84 \\
\hline \multicolumn{6}{|l|}{ Marital status } \\
\hline Unknown & 9 & 1.28 & 21 & 1.0 & Not calculated \\
\hline Single & 393 & 55.98 & 976 & 46.34 & 1.0 \\
\hline Married & 250 & 35.61 & 944 & 44.82 & 0.66 \\
\hline Divorced/separated & 50 & 7.12 & 165 & 7.83 & 0.75 \\
\hline \multicolumn{6}{|l|}{ Education } \\
\hline$\leqslant 4 \mathrm{HS} \S$ & 1 & 0.14 & 10 & 0.47 & 0.3 \\
\hline HS or GED§ & 585 & 83.0 & 1755 & 83.0 & 1.0 \\
\hline$\geqslant 1$ year college & 115 & 16.0 & 340 & 16.0 & 1.02 \\
\hline Alternate, unknown & 1 & 0.14 & 1 & 0.05 & Not calculated \\
\hline \multicolumn{6}{|l|}{ Pay grade } \\
\hline El-E3 & 281 & 40.0 & 637 & 30.3 & 1.0 \\
\hline E4-E6 & 367 & 52.3 & 1200 & 57.0 & 0.67 \\
\hline E7-E9 & 54 & 7.7 & 269 & 12.8 & 0.34 \\
\hline \multicolumn{6}{|l|}{ Duration of service $\ddagger$} \\
\hline $1-15$ months & 201 & 28.63 & 467 & 22.17 & 1.0 \\
\hline $16-32$ months & 162 & 23.08 & 459 & 21.79 & 0.82 \\
\hline $33-59$ months & 115 & 16.38 & 479 & 22.74 & 0.56 \\
\hline 60-119 months & 157 & 22.36 & 459 & 21.79 & 0.80 \\
\hline $120-414$ months & 67 & 9.54 & 242 & 11.49 & 0.64 \\
\hline CMFI & & & & & \\
\hline Support & 192 & 27.39 & 781 & 37.12 & 1.0 \\
\hline Infantry & 5 & 0.71 & 24 & 1.14 & 0.85 \\
\hline E-M repair & 85 & 12.13 & 179 & 8.51 & 1.93 \\
\hline Service & 116 & 16.55 & 283 & 13.45 & 1.64 \\
\hline Communications & 102 & 14.55 & 274 & 13.02 & 1.54 \\
\hline Health care & 116 & 16.55 & 377 & 17.92 & 1.25 \\
\hline Electrical & 52 & 7.42 & 113 & 5.37 & 1.95 \\
\hline Technical & 25 & 3.57 & 54 & 2.57 & 1.89 \\
\hline Craftsworkers & 8 & 1.14 & 18 & 0.86 & 1.81 \\
\hline Non-occupational & 0 & 0 & 1 & 0.05 & Not calculated \\
\hline Physical tasks & & & & & \\
\hline Lift/carry & & & & & \\
\hline None & 26 & 4.96 & 80 & 4.98 & 1.0 \\
\hline $1-25$ pounds & 122 & 23.28 & 458 & 28.54 & 0.76 \\
\hline $26-50$ pounds & 59 & 11.26 & 213 & 13.27 & 0.79 \\
\hline $51-75$ pounds & 78 & 14.89 & 231 & 14.39 & 0.96 \\
\hline $76-100$ pounds & 157 & 29.96 & 435 & 27.10 & 1.03 \\
\hline $101-125$ pounds & 48 & 9.16 & 101 & 6.29 & 1.35 \\
\hline $126-150$ pounds & 0 & 0 & 0 & 0 & Not calculated \\
\hline $151-175$ pounds & 24 & 4.58 & 69 & 4.30 & 0.99 \\
\hline Raises 267 pounds & 10 & 1.91 & 18 & 1.12 & 1.58 \\
\hline Push/pull** & & & & & \\
\hline None & 389 & 74.24 & 1229 & 76.57 & 1.0 \\
\hline$<130$ pounds & 77 & 14.69 & 223 & 13.89 & 1.05 \\
\hline$\geqslant 130$ pounds & 39 & 7.44 & 107 & 6.67 & 1.11 \\
\hline Foot/pound force & 19 & 3.63 & 46 & 2.87 & 1.26 \\
\hline Uses a wrench & 0 & 0 & 0 & 0 & Not calculated \\
\hline Kneeling** & & & & & \\
\hline None & 305 & 58.54 & 844 & 53.42 & 1.0 \\
\hline While shovelling, lifting & 54 & 10.36 & 143 & 9.05 & 1.03 \\
\hline While filing & 14 & 2.69 & 34 & 2.15 & 1.16 \\
\hline For prolonged periods & 148 & 28.41 & 559 & 35.38 & 0.75 \\
\hline Sitting** & & & & & \\
\hline None & 118 & 22.52 & 466 & 29.03 & 1.0 \\
\hline Any & 416 & 77.48 & 1139 & 70.97 & 0.71 \\
\hline Standing ** & & & & & \\
\hline None & 251 & 47.90 & 838 & 52.21 & 1.0 \\
\hline Any & 273 & 52.10 & 767 & 47.79 & 0.84 \\
\hline
\end{tabular}

*Cases: knee related disability discharge from the Army, 1984-94.

†OR, odds ratio.

$\ddagger$ Quintiles based on frequency distribution observed for all controls included in the data library.

$\S \mathrm{HS}$, high school; GED, Graduate Equivalency Degree.

ICMF, career management field. Support = support/administration; infantry = infantry/gun crews; e-m repair = electrical/mechanical equipment repair; service = service/supply; communications = communications/intelligence; electrical = electrical equipment repair; technical = technical/allied specialties; "non-occupational" includes trainees, prisoners, and patients.

**Available for 521 cases and 1580 controls. 
Table 3 Relative odds ratios (OR) of discharge from the Army for any knee related disability

\begin{tabular}{|c|c|c|c|c|c|c|c|c|c|}
\hline & \multicolumn{3}{|c|}{ All women* } & \multicolumn{3}{|c|}{ White women* } & \multicolumn{3}{|c|}{ Non-white women* } \\
\hline & OR† & $95 \% \mathrm{Cl} \dagger$ & $\mathrm{p} \dagger$ & ORt & $95 \% \mathrm{Cl} \dagger$ & $\mathrm{p} \dagger$ & OR† & $95 \% \mathrm{Cl} \dagger$ & $\mathrm{p} \dagger$ \\
\hline \multicolumn{10}{|l|}{ Age $\neq$} \\
\hline $17-21$ years & $1.0 \S$ & - & - & $1.0 \S$ & - & - & $1.0 \S$ & - & - \\
\hline $21-22$ years & 0.79 & 0.57 to 1.09 & 0.15 & 0.68 & 0.46 to 1.01 & 0.05 & 1.09 & 0.61 to 1.96 & 0.78 \\
\hline $22-25$ years & 0.94 & 0.70 to 1.27 & 0.69 & 0.86 & 0.60 to 1.23 & 0.41 & 1.11 & 0.64 to 1.93 & 0.71 \\
\hline $26-32$ years & 1.59 & 1.21 to 2.09 & 0.001 & 1.44 & 1.02 to 2.04 & 0.04 & 1.96 & 1.23 to 3.12 & 0.004 \\
\hline $33-60$ years & 2.44 & 1.71 to 3.47 & $<0.0001$ & 2.66 & 1.66 to 4.26 & $<0.0001$ & 2.41 & 1.37 to 4.26 & $<0.0001$ \\
\hline \multicolumn{10}{|l|}{ Race } \\
\hline White & $1.0 \S$ & - & - & - & - & - & - & - & - \\
\hline Non-white & 0.50 & 0.41 to 0.60 & $<0.0001$ & - & - & - & - & - & - \\
\hline \multicolumn{10}{|l|}{ Married } \\
\hline Nol & $1.0 \S$ & - & - & $1.0 \S$ & - & - & $1.0 \S$ & - & - \\
\hline Yes" & 0.66 & 0.54 to 0.81 & $<0.0001$ & 0.63 & 0.49 to 0.81 & 0.0003 & 0.71 & 0.51 to 0.99 & 0.04 \\
\hline \multicolumn{10}{|l|}{ Duration of service $\ddagger$} \\
\hline $1-15$ months & $1.0 \S$ & - & - & $1.0 \S$ & - & - & $1.0 \S$ & - & - \\
\hline $16-32$ months & 1.07 & 0.78 to 1.46 & 0.67 & 0.93 & 0.64 to 1.36 & 0.71 & 1.52 & 0.88 to 2.65 & 0.14 \\
\hline $33-59$ months & 0.83 & 0.55 to 1.25 & 0.36 & 0.87 & 0.53 to 1.44 & 0.60 & 0.74 & 0.35 to 1.56 & 0.43 \\
\hline $60-119$ months & 1.30 & 0.85 to 1.99 & 0.23 & 1.10 & 0.64 to 1.91 & 0.71 & 1.72 & 0.83 to 3.54 & 0.14 \\
\hline $120-414$ months & 1.43 & 0.81 to 2.55 & 0.22 & 1.23 & 0.56 to 2.72 & 0.61 & 1.82 & 0.75 to 4.44 & 0.19 \\
\hline \multicolumn{10}{|l|}{$\mathrm{CMF}^{* *}$} \\
\hline Support & $1.0 \S$ & - & - & $1.0 \S$ & - & - & $1.0 \S$ & - & - \\
\hline Infantry & 0.77 & 0.28 to 2.08 & 0.60 & 0.66 & 0.18 to 2.40 & 0.53 & 0.95 & 0.20 to 4.53 & 0.95 \\
\hline E-M repair & 1.62 & 1.11 to 2.37 & 0.01 & 1.85 & 1.15 to 2.96 & 0.01 & 1.19 & 0.60 to 2.39 & 0.62 \\
\hline Communication & 1.37 & 1.03 to 1.83 & 0.03 & 1.37 & 0.95 to 1.98 & 0.09 & 1.42 & 0.87 to 2.33 & 0.16 \\
\hline Health care & 1.10 & 0.84 to 1.45 & 0.49 & 1.27 & 0.90 to 1.79 & 0.18 & 0.79 & 0.46 to 1.24 & 0.28 \\
\hline Technical & 1.64 & 0.98 to 2.75 & 0.06 & 1.46 & 0.78 to 2.72 & 0.23 & 2.16 & 0.84 to 5.60 & 0.11 \\
\hline Electrical & 1.59 & 1.16 to 2.19 & 0.004 & 1.42 & 0.95 to 2.13 & 0.09 & 2.13 & 1.27 to 3.58 & 0.004 \\
\hline Craftsworkers & 1.55 & 0.65 to 3.72 & 0.33 & 1.53 & 0.48 to 4.92 & 0.47 & 1.50 & 0.40 to 5.63 & 0.55 \\
\hline Non-occupational & 0 & - & - & 0 & - & - & 0 & - & - \\
\hline \multicolumn{10}{|l|}{ Pay grade } \\
\hline El-E3 & $1.0 \S$ & - & - & $1.0 \S$ & - & - & $1.0 \S$ & - & - \\
\hline E4-E6 & 0.62 & 0.45 to 0.87 & 0.01 & 0.69 & 0.46 to 1.03 & 0.07 & 0.49 & 0.28 to 0.86 & 0.01 \\
\hline E7-E9 & 0.20 & 0.12 to 0.35 & $<0.0001$ & 0.25 & 0.12 to 0.50 & $<0.0001$ & 0.14 & 0.06 to 0.33 & $<0.0001$ \\
\hline
\end{tabular}

*All women: $n=692$ cases, $n=2080$ controls. Whites: $n=469$ cases, $n=1050$ controls. Non-whites: $n=223$ cases, $n=1030$ controls.

†OR, odds ratio; $95 \% \mathrm{Cl}, 95 \%$ confidence interval; $p$, $p$ value.

$\ddagger$ Quintiles based on distribution observed among all controls in data library.

$\S$ Referent category.

IIncludes never married and no longer married.

**CMF, career management field. Support = support/administration; infantry = infantry/gun crews; e-m repair = electrical/mechanical equipment repair; service $=$ service/supply; communication $=$ communications/intelligence; electrical $=$ electrical equipment repair; technical $=$ technical/allied specialties;

"non-occupational" includes trainees, prisoners, and patients.

be among the lower pay grades (E1-E3) compared to controls. The three most common CMFs for both cases and controls were support/administration, service/supply, and health care. Cases were slightly over represented among the electrical/mechanical equipment repair, electrical equipment repair, and craftsworker CMFs. The physical tasks required of cases and controls were very much alike, reflecting their similarity with respect to the distribution of CMFs. Cases were somewhat more likely to be in jobs associated with lifting weights of at least 100 pounds, and were slightly more likely than controls to be in jobs associated with sitting or standing.

In single predictor models, non-white race, being married, having longer duration of service, and higher pay grade were associated with lower risk of knee related disability discharge (table 2). Certain of the CMFs were associated with higher risk of disability discharge relative to the administration/support CMF. The CMFs with the highest odds ratios compared to support/administration were electrical/mechanical equipment repair, communications/intelligence, technical/allied specialties, electrical equipment repair, and service/supply. None of the specific job tasks considered met our definition of practical or statistical significance (table 2).

\section{Multivariable analyses}

In addition to quintiles of age and race (white/non-white), the final multivariable model included marital status (married yes/no), CMF, and pay grade. We included duration of service, in quintiles, because of its influence on the magnitude of the coefficients of the other terms in the model (table 3).
Several terms that were only weakly associated with risk of knee related disability discharge in single predictor models were more strongly associated with risk when other factors were controlled in the multivariable setting. Women in the two oldest quintiles of age (26-32 years and 33-60 years) experienced approximately twice the risk relative to those in the youngest age group. Non-white women had a 50\% lower risk of knee related disability discharge relative to white women, and there was a $44 \%$ lower risk for married compared to unmarried women. Although no job task showed an effect on the risk of knee related disability discharge, several of the CMFs did show higher risks than administration/support. Three CMFs had about a 60\% higher risk: technical/allied specialties (OR $=1.64,95 \%$ CI: 0.98 to 2.75$)$; electrical/ mechanical equipment repair $(\mathrm{OR}=1.62,95 \% \mathrm{CI}$ : 1.11 to 2.37); and electrical equipment repair ( $\mathrm{OR}=1.59,95 \% \mathrm{CI}$ : 1.16 to 2.19). Even after controlling for age, duration of service and CMF, women in pay grades E4-E6 had a 40\% lower risk than women in grades El-E3, and women in grades E7-E9 had an 80\% lower risk than women in the lowest three pay grades. The Hosmer-Lemeshow goodness of fit statistic showed adequate fit of this model to the data (statistic $=11.2$, $p=0.20$ on 8 degrees of freedom).

As table 3 shows, there was evidence of effect modification by race for risks associated with higher pay grades (where the decrease in risk for grades E4 and above relative to E1-E3 was greater for non-whites than whites) and certain CMFs (electrical/mechanical equipment repair; health care; technical/allied specialties; electrical equipment repair). For 
white women, the Hosmer-Lemeshow statistic indicated the model fits $(p=0.50)$. The model did not fit for non-white women; the value of the test statistic was $17.32, p=0.03$ for 8 degrees of freedom.

The strong interrelations between age, duration of service, and pay grade led to numerical difficulties in constructing models stratified by one variable that included either of the other two. As a result of the high correlations among these terms $(r=0.77$ for age and duration of service, and $r=0.69$ for age and pay grade), it was necessary to drop the remaining two time related covariates from models stratified by the third covariate.

The results from the stratified analyses were largely the same as the results from the main model, and so are not presented in a separate table. In analyses stratified by age group (17-22 years, 23-32 years, and 33-60 years), there were differences from the main analysis for non-white race, marital status, and CMF, as follows: the $40-50 \%$ lower odds of knee related disability discharge associated with non-white race observed in the main analysis was similar for women in the two youngest groups $(\mathrm{OR}=0.59, \mathrm{CI}: 0.42$ to 0.82 , and $\mathrm{OR}=0.50$, CI: 0.39 to 0.66 , respectively), but the OR for women aged 33-60 years was 0.39 (CI: 0.25 to 0.61 ). The lower odds associated with being married versus not married observed in the main analysis was strongest among the youngest women, whose OR was 0.40 (95\% CI: 0.26 to 0.60 ). Women aged $23-32$ years and 33-60 years who were married, each had odds of disability about $20 \%$ lower than that of unmarried women of the same ages ( $\mathrm{OR}=0.78, \mathrm{CI}$ : 0.60 to 1.00 , and OR $=0.74$, CI: 0.41 to 1.16 , respectively.) In the main analysis, women in the electrical repair CMF had odds of knee related disability discharge $60 \%$ higher than women in the support/administration CMF. On stratifying by age, the higher odds for women in support/administration jobs seemed to be concentrated among 23-32 year olds. The ORs and 95\% CI for women in each age group were 1.24 (CI: 0.70 to 2.18), 1.98 (CI: 0.99 to 3.94 ), and 0.86 (CI: 0.26 to 2.86 ), respectively.

The results for race and marital status were similar when we stratified by pay grade (E1-E3, E4-E6, and E7-E9) instead of age group. Non-white women in grades E1-E3 had 40\% lower risk of knee related disability compared to white women in these grades (CI: 0.44 to 0.83 ), while non-white women in grades E7-E9 were at 70\% lower risk compared to white women (CI: 0.17 to 0.63 ). The marital status effect was evident for women in grades El-E3 (OR $=0.54, \mathrm{CI}: 0.37$ to 0.78$)$ and E7-E9 (OR $=0.52$, CI: 0.28 to 0.96 ), but not for women in the middle pay grade group (OR $=0.96$, CI: 0.76 to 1.22 ). The $40 \%$ higher odds of disability for women in the electrical/mechanical equipment repair versus the support/administration CMF seemed to be driven by a doubling of risk among women in grades $\mathrm{E} 1-\mathrm{E} 3 \quad(\mathrm{OR}=2.06, \mathrm{CI}: 1.15$ to 3.68 , compared to $\mathrm{OR}=1.40, \mathrm{CI}: 0.82$ to 2.39 for E4-E6, and OR $=0.80$, CI: 0.16 to 3.97 for E7-E9). The 40\% higher odds of disability among technical/allied specialties when we considered all women together seemed to be driven by an increase in risk for women in grades E4-E6. For this group, the OR was 1.91 (CI: 0.97 to 3.75), whereas the odds ratios for women in the other two pay grade groups were similar to each other (1.33 and 1.46), but imprecisely measured. Women in the service/supply CMF in grades E1-E3 and E4-E6 had slightly higher odds of disability compared to women in the support/administration CMF. The $65 \%$ increase in risk noted in the main analysis for service/ supply seems to have been driven by the increase in risk for women in grades E7-E9 (OR $=2.63$, CI: 0.96 to 7.22 ).

In models stratified by duration of service (1-32 months, 33-119 months, and $\geqslant 120$ months), odds ratios associated with non-white race and marital status were similar to those from the main analysis. Most of the estimated risks associated with CMF within categories of duration of service were also similar to the main results, except for electrical/mechanical equipment repair, where the effect seemed to be concentrated among those with the shortest service duration $(\mathrm{OR}=2.22$, CI: 1.37 to 3.62; $\mathrm{OR}=1.12$, CI: 0.56 to 2.33 for 33-119 months; and OR $=0.59$, CI: 0.12 to 2.82 for $\geqslant 120$ months). Similarly, the electrical repair CMF showed a $60 \%$ increase in risk compared to support/ administration in the main analysis, but the highest odds of discharge were for women with at least 10 years of service $(\mathrm{OR}=13, \mathrm{CI}: 2.39$ to 72 ; OR $=1.74, \mathrm{CI}: 1.14$ to 2.67 for $1-32$ months; and $\mathrm{OR}=1.28$, CI: 0.77 to 2.11 for 33-119 months.)

\section{DISCUSSION}

While a number of researchers have previously noted sociodemographic differences in risk of occupational injury, those reports primarily represented the results of descriptive analyses. $^{3} 4^{10} 23-31$ The results of this study show that there exist important differences in risk of knee related disability discharge from the US Army according to both occupational and demographic characteristics.

We observed that enlisted women at higher pay grades were at reduced risk of knee related disability discharge from the Army even after controlling for age, race, duration of service, and job characteristics. Few other characteristics of occupation, including the specific tasks associated with job codes, appeared to have an impact on the risk of knee related disability discharge. However, the presence of complex interrelations among sociodemographic characteristics in this population may impede the detection of independent effects of occupational characteristics.

Both the CMFs and the specific job tasks we analysed were mapped from the PMOS. Neither covariate exhibited a strong effect on the risk of knee related disability discharge. In contrast, other researchers have noted differences in risk of musculoskeletal disability generally, and knee related disability in particular, that vary according to PMOS within the Army. ${ }^{13}{ }^{19}$ However, those analyses did not take into account either duration of service or pay grade, two characteristics that may be more predictive of the type of work actually performed, and hence, the amount of physical risk incurred, than the job title (PMOS) alone. It may also be the case that pay grade is associated with other determinants of disability discharge, separate from its correlation with physical risk. For example, if more highly trained personnel are perceived to be more valuable to the Army, and are awarded higher pay grades, there may be an institutional bias against discharging such personnel in questionable cases.

A limitation of work exposures based on job title in this and in earlier research is that they rely on group level exposure assessment. While PMOS is recorded for nearly every soldier, and expected job tasks are known for each job code, it is not known how many of the expected tasks are actually performed, or if the assigned and recorded PMOS accurately reflects the job being done by any individual soldier. As a result, there is likely to be a substantial amount of misclassification with respect to the work exposures we evaluated. In contrast, duration of service and pay grade are both individual level measures, which may explain why they were more important in multivariable models than were work exposures or CMF.

Race seemed to exert a substantial modifying effect on the risks associated with work characteristics in these data. The relation between risk of disability discharge and CMF was either greatly enhanced or reversed when white and non-white women were evaluated separately. These differences were evident in models that controlled for demographic characteristics other than race, and for other work characteristics, including pay grade and duration of service. Possible explanations for the racial differences in risk of disability discharge include: (1) the expected work tasks actually performed by soldiers in certain CMF are distributed differently, and along racial lines; (2) there are relevant differences in the anatomical structure of the knee or leg of white and non-white women, leading to differences in risk of injury, 
Main messages

- Sociodemographic factors had larger effects than occupational characteristics on risk of knee related disability discharge from the US Army.

- Interactions between sociodemographic and occupational factors suggest subgroups with differing risk levels may be identified.

\section{Policy implications}

- Occupational risk factors are modifiable.

- The identification of higher risk subgroups within the population suggests targeted interventions may be developed to reduce the impact of occupational injury and disability.

ability to heal following physical stresses, or both; (3) race is an indicator of one or more variations in the disability determination process.

We also evaluated effect modification by age, duration of service, and pay grade. Not surprisingly, the strong interrelation among these covariates hampered our ability to model their individual effects. Nevertheless, we did find evidence of changes in the risk of knee related disability associated with specific jobs across categories of these variables. This interaction suggests that job tasks within CMF, and therefore, work related exposures that determine risk, may be influenced by rank or seniority. More detailed evaluations of specific jobs and their tasks, with analyses possibly restricted to various demographic subgroups, may be helpful in sorting out these complex associations.

The VASRD codes used to identify cases include some reasons for disability discharge that clearly involve the knee, while others are more generally related to the lower leg. This mixture of outcomes probably reduced our ability to identify specific determinants of knee related disability discharge. However, when we re-ran the final multivariate model for the subset of 459 women discharged for recurrent subluxation of the knee, the patterns of risks for disability discharge were similar to those described above. The only notable differences from the results of the main analysis were for duration of service, where the odds ratios for the subset of cases of recurrent subluxation of the knee were all around two (data not shown).

Information for this study was abstracted from a database with administrative origins, and the frequently documented shortcomings of administrative data apply. These include a lack of information regarding quality control procedures, missing data, and coding schemes not developed for the convenience of the researcher (for example, too many or too few codes for certain data elements).

In summary, we aimed to identify the determinants of occupational knee related disability among enlisted women in the US Army, and we found that risks varied according to both demographic and work related characteristics. These determinants probably include risk factors for injury and factors that influence the progression from injury to disability, including the disability determination process (fig 1). By focusing on disability as an outcome, we identified the subset of knee injuries that were severe, thus representing a serious and costly social and health issue for all involved. As we were able, using the TAIHOD, to identify interactions between occupational and sociodemographic determinants of risk, it may be possible to identify specific high risk work tasks or occupational subgroups that could be studied in more detail to identify determinants of knee related disability and to target appropriate interventions.

\section{Authors' affiliations}

S I Sulsky, K A Mundt, C Bigelow, Applied Epidemiology, Inc. Amherst, MA, USA

P J Amoroso, US Army Research Institute of Environmental Medicine, Natick, MA, USA

\section{REFERENCES}

1 US Bureau of Labor Statistics. Incidence rates of nonfatal occupational injuries and illnesses by selected industries and case types. US Bureau of Labor Statistics, 2000

2 Eckenfelder DJ. The success of Cheeseborough-Ponds: a ten step strategy for loss prevention. Risk Management May 1992:59-64.

3 Ross J, Woodward A. Risk factors for injury during basic military training. Is there a social element to injury pathogenesis? J Occup Med 1994; $36: 1120-6$

4 Amoroso PJ, Canham ML. Disabilities related to the musculoskeletal system: Physical Evaluation Board data. Atlas of injuries in the US Armed Forces. Mil Med 1999;164(suppl 8):4-1-4-73

5 Smith GS, Dannenberg AL, Amoroso PJ. Hospitalization due to injuries in the military: evaluation of current data and recommendations on its use for injury prevention. Am J Prev Med 2000;18(3S).

6 Jensen LK, Eenberg W. Occupation as a risk factor for knee disorders. Scand J Work Environ Health 1996;22: 165-75.

7 Jensen LK, Mikkelson S, Loft IP, et al. Work-related knee disorders in floor layers and carpenters. J Occup Environ Med 2000;42:835-42.

8 Leino P, Hasan J, Karppi S-L. Occupational class, physical workload, and musculoskeletal morbidity in the engineering industry. $\mathrm{Br} J$ Ind Med 1988;45:672-81.

9 Thelin A. Hip joint arthrosis: an occupational disorder among farmers Am J Ind Med 1990;18:339-43.

10 Vingard E, Alfredsson L, Goldie l, et al. Occupation and osteoarthrosis of the hip and knee: a register-based cohort study. Int J Epidemiol 1991;20:1025-31

11 Klunder KB, Rud B, Hansen J. Osteoarthritis of the hip and knee joint in retired football players. Acta Orthop Scand 1980;51:925-7.

12 Panush R, Schmidt C, Caldwell J, et al. Is running associated with degenerative joint disease? JAMA 1986;255:1152-4

13 Feuerstein M, Berkowitz SM, Charles A, et al. Musculoskeletal-related disability in US Army personnel: prevalence, gender and military occupational specialties. J Occup Environ Med 1997;1:68-78.

14 Patnaik P. Case control study of disabling knee injuries in the United States Army: classification of injury for etiological research. Biostatistics and Epidemiology, University of Massachusetts, Amherst, Massachusetts, 75, 1998.

15 Sulsky SI, Mundt KA, Bigelow C, et al. Case-control study of disabling occupational knee injury in the US Army. The role of gender, race and age. Am J Prev Med 2000;18(3S):103-11.

16 Burdorf A, Rossignol M, Fathallah FA, et al. Challenges in assessing risk factors in epidemiologic studies on back disorders. Am J Ind Med 1997; 32:142-52.

17 Williams RE, Amoroso P, Mundt KA, et al. Physical tasks of military occupational specialties as risk factors for knee-related disability discharge. Natick, MA: US Army Medical Research and Material Command, 2000.

18 Anon. Military occupational classification and structure. Washington, DC: Department of the Army, Headquarters, 1995.

19 Williams RE. Physical tasks of military occupational specialties as risk factors for disabling knee injury. Biostatistics and Epidemiology. University of Massachusetts, Amherst, Massachusetts, 96, 1998

20 Statistical Analysis System. Cary, NC: SAS Institute, 1996.

21 Fleiss JL. Statistical methods for rates and proportions, 2nd edn. New York: John Wiley and Sons, 1981.

22 Hosmer DW, Lemeshow S. Applied logistic regression, 1st edn. New York, NY: John Wiley and Sons, Inc., 1989

23 US Bureau of Labor Statistics. Number of non-fatal occupational injuries and illnesses involving days away from work by selected worker characteristics and industry division. US Bureau of Labor Statistics, 1996.

24 Bresnitz EA, Frumkin H, Goldstein L, et al. Occupational impairment and disability among applicants for Social Security disability benefits in Pennsylvania. Am J Public Health 1994;84:1786-90.

25 Anon. Surveillance for nonfatal occupational injuries treated in hospital emergency departments-United States, 1996. Morb Mortal Wkly Rep 1998:302-7

26 Cooper C, McAlindon T, Coggon D, et al. Occupational activity and osteoarthritis of the knee. Ann Rheum Dis 1994;53:90-3.

27 Felson DT, Hannan MT, Naimark A, et al. Occupational physical demands, knee bending and osteoarthritis: results from the Framingham Study. J Rheumatol 1991;18:1587-92.

28 Jones BH, Cowan DN, Tomlinson JP, et al. Epidemiology of injuries associated with physical training among young men in the Army. Med Sci Sports Exerc 1993;25:197-203.

29 Kelsh MA, Sahl JD. Sex differences in work-related injury rates among electric utility workers. Am J Epidemiol 1996;143:1050-8.

30 Tomlinson JP, Lednar WM, Jackson JD. Risk of injury in soldiers. Mil Med 1987;152:60-4

31 Zwerling C, Sprince NL, Ryan J, et al. Occupational injuries: comparing the rates of male and female postal workers. Am J Epidemiol 1993; 138:46-55. 